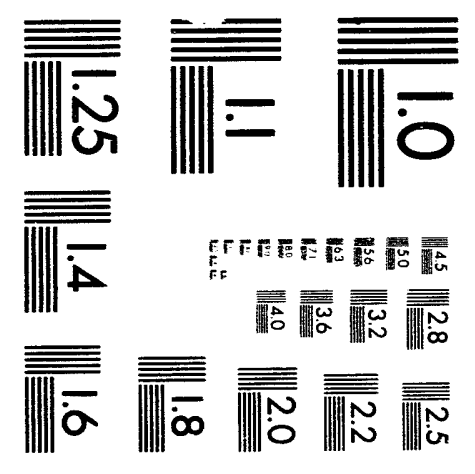



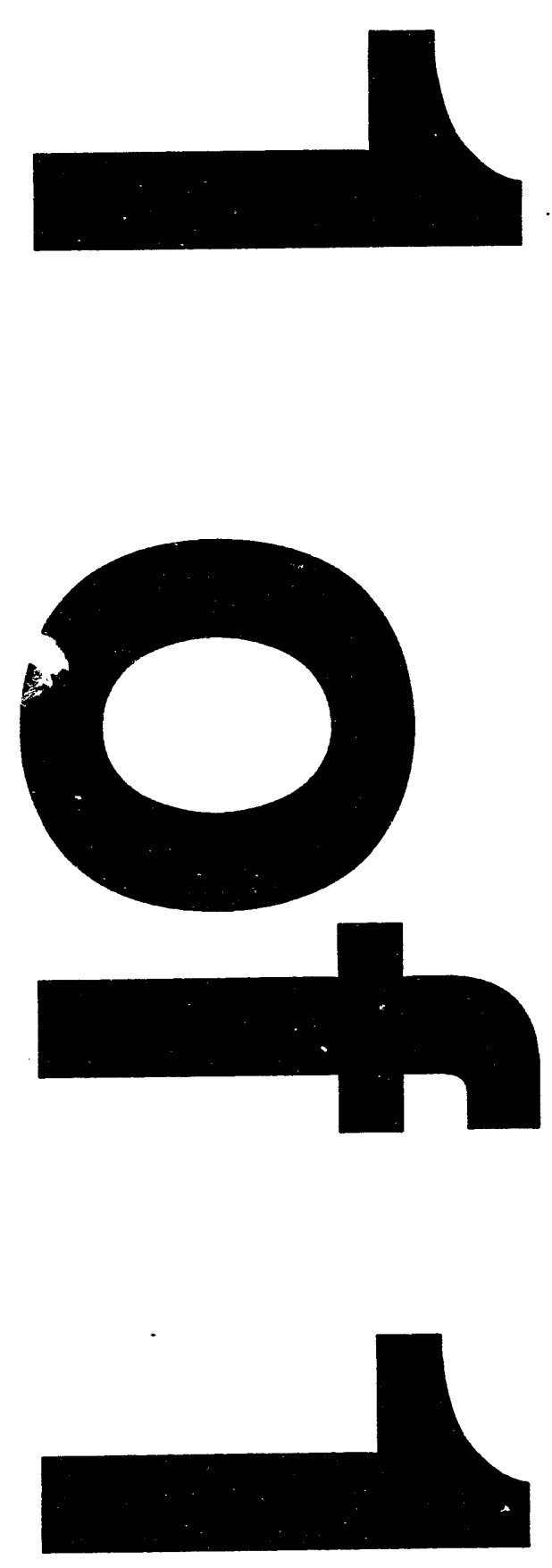


\title{
An Experimental Study on the Effects of Compressive Stress on the Fatigue Crack Growth of Low-Alloy Steel
}

\author{
D. P. Jones, Advisory Engineer \\ R. G. Hoppe, Manager Engineering Mechanics \\ Bettis Atomic Power Laboratory \\ Westinghouse Electric Corporation \\ West Mifflin, PA 15122-0079 \\ J. L. Hechmer, Advisory Engineer \\ Babcock \& Wilcox Company \\ Barberton, Ohio 44203 \\ B. A. James \\ Metallurgy Department \\ Colorado School of Mines \\ Golden, Colorado 80401
}

\section{DISCLAIMER}

\begin{abstract}
This report was prepared as an account of work sponsored by an agency of the United States Government. Neither the United States Government nor any agency thereof, nor any of their employees, makes any warranty, express or implied, or assumes any legal liability or responsibility for the accuracy, completeness, or usefulness of any information, apparatus, product, or process disclosed, or represents that its use would not infringe privately owned rights. Reference herein to any specific commercial product, process, or service by trade name, trademark, manufacturer, or otherwise does not necessarily constitute or imply its endorsement, recommendation, or favoring by the United States Government or any agency thereof. The views and opinions of authors expressed herein do not necessarily state or reflect those of the United States Government or any agency thereof.
\end{abstract}

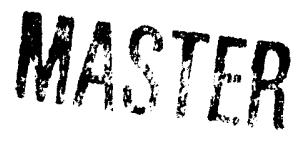




\title{
An Experimental Study on the Effects of Compressive Stress on the Fatigue Crack Growth of Low-Alloy Steel
}

\author{
D. P. Jones \\ R. G. Hoppe \\ J. L. Hechmer \\ B. A. James
}

\begin{abstract}
A series of fatigue crack growth rate tests was conducted in order to study the effects of negative stress ratio upon the fatigue crack growth rate of low-alloy steel in air environment. The tests used four-point bend specimens in order to simulate linear stress distributions typical of many pressure vessel applications. This type of testing adds to the knowledge on negative stress ratio effects for low-alloy steels that in the past have been obtained from uniform tension-compression tests. Additionally, the applied bending stress range was varied from low values of applied stress to high values of applied stress over twice the yield strength. Load control was used for tests for which the stress range was less than twice the yield strength and deflection control was used for the higher stress range tests. The crack geometries involved were both short and long fatigue cracks started at notches and tight fatigue cracks for which crack closure could occur over the full crack face.

The results are presented in terms of the stress intensity factor ratio $R=K_{\text {MN }} / K_{\text {max }}$. The negative R-ratio test results were correlated to an equation of the form da/dN $=C[\Delta K /(A \cdot R)]^{n}$ where $A, C$, and $n$ are curve fitting parameters. It was found that the effects of negative R-ratio on the fatigue crack growth rates for even the high stress range tests could be bounded by correlating the above equation to only positive R-ratio test results and extending the resulting equation into the negative R-ratio regime.
\end{abstract}


WAPD-T-2973

Page 2

\title{
An Experimental Study on the Effects of Compressive Stress on the Fatigue Crack Growth of Low-Alloy Steel
}

\author{
D. P. Jones \\ R. G. Hoppe \\ J. L. Hechmer \\ B. A. James
}

\section{INTRODUCTION}

Fatigue crack growth [FCG] technology has emerged as a very powerful tool to evaluate the fatigue life of pressure vessel and piping equipment. This is particularly true of welded construction for which there is a finite possibility of the existence of flaws due to the welding and fabrication processes. FCG methodology is primarily based on correlations between the FCG rate (da/dN where $a$ is the crack length and $N$ the number of cycles at a stress range $\sigma_{\text {MAX }}$ to $\sigma_{M N N}$ ) and the range of the fracture mechanics stress intensity factor $\Delta K$ for positive stress ratios, $R=\sigma_{\text {MIN }} / \sigma_{\text {MAX }}$. However many pressure vessel and piping applications which satisfy the fatigue design requirements of the ASME Boiler and Pressure Vessel Code involve negative R-ratios for which the elastically calculated primary-plus-secondary stress difference ranges can be as high as twice the yield strength. The test program reported on herein is directed at confirming the use of the FCG technology for negative R-ratio applications under conditions such that the primary-plus-secondary stress difference ranges are produced by bending and are as high as twice the monotonic yield strength of the material.

FCG rate test results are presented for R-ratios of $0,-1 / 2,-1$, and -2 under conditions of load and deflection control and at various stress range levels. The results confirm that the equation developed by Eason et. al. [1] to correlate positive R-ratio results can be used to correlate the negative R-ratio results obtained here even when the primary-plus-secondary stress difference range is as high as twice the yield strength.

\section{BACKGROUND}

Negative R-ratio effects are defined as the contribution, if any, of the compressive portion of the stress cycle to additional crack extension beyond that contributed by the tensile portion. Some material and temperature combinations exhibit negative R-ratio effects while others do not.

Negative R-ratio effects where they occur are considered to be primarily caused by crack closure. Numerous negative R-ratio studies have been conducted using center-cracked tension panels and other suitable specimen geometries $[2,3,4]$. These studies show that under conditions which comply with linear elastic fracture mechanics limitations, the negative $R$-ratio effects can be correlated on the basis of $K_{\max }$ suggesting that the negative portion of

Numbers in brackets refer to list of references at end of text. 
WAPD-T-2973

Page 3

the cycle does not contribute to crack growth. This phenomenon is attributed to the fact that under compressive loads the crack faces close on themselves thus prohibiting crack growth.

There is a great deal of scatter associated with negative R-ratio test results however and this scatter is thought to be due to the variation of the mechanical crack closure effects due to crack-tip plasticity, crack-face conditions affecting closure, and differences in specimen design creating non-uniform closure along the crack face. For example, bending stresses may cause non-uniform closure while tension stresses may cause a uniform closure. In addition, large variations in the negative R-ratio results are observed in situations where the crack-tip plastic zone size is large compared to the crack size such as might occur in local regions of stress and strain concentration in pressure vessel design applications.

In the present study, results are presented which address the issues of stress distribution (these tests are for bending stress fields as opposed to the usual tension stress in the centercracked panel); crack geometry (the cracks tested included both small cracks emanating from notches and tight fatigue cracks for which the potential of crack closure could occur over the full crack face); and local yielding controlled by deflection (to simulate a local strain concentration for which the overall structure is elastic as permitted in pressure vessel design).

\section{EXPERIMENTAL PROCEDURES}

The experiments were conducted at the Babcock \& Wilcox Research and Development Division in Alliance, Ohio. The experiments were conducted on a closed loop servohydraulic testing machine built by the MTS Corporation in Minneapolis, Minnesota. The specimens were loaded in the four-point bending fixture shown in Figure 1. The fixture was held stationary at one end to avoid collapse of the fixture during the test. The tests were conducted in air at room temperature. The loads were applied in a sinusoidal waveform at a frequency that varied between 0.5 and 15 cycles/second. Applicable procedures from ASTM E647-88a[5] and ASTM E399[6] were used for specimen preparation and fatigue crack growth testing.

The crack length was measured in three ways. The first was optically using travelling microscopes stationed on each side of the specimen. The average of the two readings was used as the crack length. The second method was by compliance measurements using a calibration curve of crack-length versus compliance obtained analytically and confirmed experimentally. A third method was used in the high stress range tests such that the crack length was measured directly from indications on the crack face produced by heat-tinting and beach-marking processes during the test. Figures 8 and 9 show the photographic enlargements which were used to facilitate these measurements. The defect length used in the data assessment was determined from whichever method provided the best values for each specimen.

The specimen geometry for the four-point bend bars is described in Figures $2 a$ and $2 b$. The specimens used in the tests for which the applied stress range is over twice the yield strength (tests $11-4$ and II-5) were side-grooved as shown in the figure in order to control the direction of crack growth. The chemistry and mechanical properties for the materials tested are provided in Table 1. 
Since crack closure is considered to be the predominant mechanical effect in negative R-ratio FCG testing, two techniques were used to produce the initial cracks in the beams. The first technique utilized the familiar process of electro-discharge machining (EDM) a notch followed by a fatigue precracking procedure to sharpen the crack from the base of the notch to the desired pre-test length. The precrack loads were maintained well below the test loads and the R-ratio for precracking was 0.0 . The second technique for intially cracking the beam is explained with the help of Figure $2 \mathrm{~b}$. Here defects were initiated by fatigue precracking a notch in a prolongation on the beam. The cracks were grown in fatigue to the desired length and the prolongation machined off prior to the negative R-ratio testing. In this way a comparison can be made to see if crack closure and hence negative R-ratio effects are a function of the tightness of the crack over its full length.

The test matrix is shown in Table II along with the initial values of the outer-fiber bending stress in the beam calculated from the formula

$$
\sigma=3.0 \mathrm{PS} /\left(\mathrm{W}^{2} \mathrm{~B}_{\mathrm{N}}\right)
$$

where $P$ is the load, $S$ is the distance between load points, $W$ is the width of the specimen, and $B_{N}$ is the thickness through the beam at the cracked section. The objective was to control the deflections in the beam such that the elastically calculated stress in the beams are comparable to the elastically calculated stresses as are limited by the structural design rules used in the ASME Boiler \& Pressure Vessel Code. Under such rules the defect is ignored in the design calculations as it is in Equation (1).

A total of eleven specimens were tested as indicated in Table II. All of the tests were conducted in air at room temperature. Of the eleven specimens two were cycled such that the range of the outer fiber stress (or $\Delta \sigma$ ) produced the elastically calculated stress approximately equal to the monotonic yield stress of the material at room temperature. Two additional tests were run where the $\Delta \sigma$ was greater than twice the yield strength. These last two tests were run in deflection control. From a calibration test of an uncracked specimen, the deflection to cause outer fiber stress range of $2 S_{y}$ (where $S_{y}$ is the $0.2 \%$ off-set monotonic yield strength of the material) was determined by a clip gage which measured the relative motion between the reference bar and the specimen. Tests $\|-4$ and $\|-5$ were controlled to the selected deflection range and corresponding values of the load $P$ were recorded for each cycle. The stress ranges reported in Table II were calculated from the reported initial values of $\Delta P$, the beam geometry, Equation (1), and the average monotonic yield stress of the material from Table I, $72.6 \mathrm{ksi}$.

\section{Calibration Test}

Structural design stress limits are based on elastically calculated stresses in the non-defected component. In order to confirm the elastic calculations for these tests and to provide a check-out of the apparatus, a non-cracked calibration specimen was tested in the fixture. The objective of the calibration test was to provide the load deflection information for the noncracked beam that will provide stress ranges up to the primary-plus-secondary stress range 
limit of $2 S_{y}$. A508-Class 2 steel cyclically strain hardens to a moderate degree. Hence the $0.2 \%$ off-set cyclic yield strength is expected to be somewhat higher than the corresponding monotonic value. For this reason tests $\|-4$ and $\| 1-5$ were run at somewhat greater than $2 S_{y}$ ranges.

Strain gages were placed on the top and bottom of the beam and the beam loaded until $0.2 \%$ permanent strain was reached on the tension side of the beam and then the load reversed until $0.2 \%$ permanent strain was measured on the other side of the beam. The crack growth tests were load controlled such that the test load was at the desired fraction of the load which produced $0.2 \%$ tensile yielding in the outer fiber as measured in the calibration test. The $\pm 2 S_{y}$ tests were controlled to the deflection that would produce the desired elastically calculated stress and strain in the outer fiber of the uncracked beam. This method of loading is considered consistent with the strain controlled fatigue cycling associated with and stress concentration regions such as at structural discontinuity regions.

\section{Method of Data Analysis}

Fatigue crack grotvth rate $(\mathrm{da} / \mathrm{dN})$ and $\Delta K$ are not measured quantities but calculated from the measured quantities of load, crack length, and cycles. ASTM E647-88(a) [5] provides methods for calculating da/dN given the crack length (a) versus cycles ( $N$ ) data points. In all cases the ASTM secant method was used to produce the FCG rate data because it provided a more consistent interpretation of the data than did the other methods.

For purposes of correlations to fatigue crack growth rate, the stress intensity factor is also required. The formula for the stress intensity factor for an edge crack in a four-point bend bar was taken from Tada [7] and is

$$
\left.K_{1}=\left(3 P S / 2 W^{2}\right) \sqrt{B B_{N}}\right) f(a / W) \sqrt{\pi a}
$$

In this equation the correlation factor $f(a / M)$ is given by

$$
f(a / W)=1.122-1.40 a / W+7.33\left(a / W^{2}-13.08\left(a / W^{3}+14\left(a / W^{4}\right.\right.\right.
$$

and $a$ is the crack length, $W$ is the specimen width, $B$ is the specimen thickness, $B_{N}$ is the net thickness accouting for side-grooves, $P$ is the total load and $S$ is the distance between load points as in Figure 2.

\section{TEST RESULTS}

The results of tests $1-1$ through $1-6, \|-1$ and II-2 are provided in Figure 3 . This figure along with Table III gives the results of the regression fit of the $\mathrm{da} / \mathrm{dN}$ versus $\Delta \mathrm{K}$ data to a powerlaw relation of the form 
WAPD-T-2973

Page 6

$$
d a / d N=C_{1} \Delta K^{n}
$$

where $C_{1}$ and $n$ are curve fitting parameters. It should be noted that, throughout this report $\Delta K$ is defined as the total stress intensity factor range including the compressive portion. This definition is different than that employed in Section 3.2.8 of ASTM E647-88a, but is consistent with applications.

The coefficient $C_{1}$ and exponent $n$ for each test are listed in Table III in the units such that $\mathrm{da} / \mathrm{dN}$ is in/cycle and $\Delta \mathrm{K}$ is psi Vin. From this table it can be observed that the values of $n$ are nearly the same for Tests $1-1$ thru I-6, II-1 and II-2. Therefore, a convenient way to develop a negative R-ratio correlation is to fit each test to a power-law relationship given a fixed value of $n$ equal to the average $n$ from the first eight tests. This was done with the nonlinear curve fitting program called NLFIT based on the Marquardt paper [8]. The coefficients produced by this process are called $\bar{C}_{1}$ in Table III corresponding to the average $n$ of 3.0789 . The negative R-ratio results are thus obtained by normalizing each curve-fit by the results for the $R=0$ test which is

$$
d a / d N=1.2298 \times 10^{-19} \Delta K^{3.0789}
$$

The ratio of the corresponding correlation for each negative $R$-ratio test provides a factor $F_{R}$ which is defined as the FCG rate for any R-ratio divided by the FCG rate for $R=0$. Thus, $F_{R}$ the ratio of Equation (4) to Equation (5) or

$$
F_{R}=\bar{C}_{1} /\left(1.2298 \times 10^{-19}\right)
$$

\section{DEVELOPMENT OF A NEGATIVE R-RATIO CORRELATION}

Eason et.al. [1] correlated positive R-ratio results to an equation of the form

$$
d a / d N=q \Delta K(A-R)]^{n}
$$

The curve fitting parameters $C, A$, and $n$ were fit over a broad range of FCG rate test data for positive R-ratios. Eason et.al. found that $A=2.88$ for the best correlation of positive R-ratio data. Normalizing Equation (7) to the $R=0$ case of Equation (7) provides a negative R-ratio equation in terms of the factor $F_{R}$ consistent with the method of developing Equation (6). That is, from Equation ( 7 ) for $R=0.0$

$$
d a / d N=C[\Delta K A]^{n}
$$

and dividing Equation (7) by Equation (8) gives 
WAPD-T-2973

Page 7

$$
F_{R}=[A(A-R)]^{n}
$$

where $A$ is the only curve fitting parameter for a fixed value of $n$. The data developed from Equation (6) can thus be fit directly to Equation (9) to determine the appropriate value of $A$. Using the non-linear statistical fitting program NLFIT [8] and all eleven tests as shown in Table III, the value of $A$ was found to be 1.22986 over the range $0 \leq R \leq-2$. The standard deviation on $A$ for the data given in Table IV is 0.097437 . The data and correlation are shown in Figure 4. If only the first eight points are used, i.e. the points that are for stresses below yield, the value of $A$ is about 1.1 .

Plotted in Figure 5 is a comparison of Equation (9) with $A=1.22986$ with the Eason et.al. correlation for positive R-ratio $(A=2.88)$ with the data. Although the fit is not as good as provided by Equation (9) with $A=1.22986$, it is conservative compared with most of the data and provides a reasonable bound to the higher stress range data.

\section{EFFECT OF NOTCHES VERSUS CRACKS}

Since negative R-ratio effects are considered to be principally caused by crack closure, it is suggested that a tight crack should produce more significant crack closure and hence negative R-ratio effects. Tests I-1 through I-6 utilized notches as crack starters while $\mid 1-1$ and II-2 were tight cracks. Figure 6 shows a comparison between these tests, and the results suggest that these crack and notch geometries do not significantly alter negative R-ratio effects.

\section{EFFECT OF HIGH STRESS RANGES}

Figure 7 provides a comparison of the $R=-1.0$ tests; i.e. tests $1-2,1-6,\|-2\|-$,4 , and $11-5$. Test $1-2$, and $1-6$ were at stress ranges between 1.2Sy an 0.4Sy while tests $11-4$ and $11-5$ were for $\Delta \sigma$ much greater than the $2 S_{y}$ value allowed by the ASME Boiler and Pressure Vessel Code Sect. III (i.e. $160 \mathrm{ksi}$ versus $100 \mathrm{ksi}$ ).

The results of these tests suggest that there is a significant difference between the FCG rate curves when small and large stress ranges are encountered. The results from II-4 and II-5 suggests that it makes some difference if the initial stress cycle closes or opens the crack (i.e., less benefit is seen when the first cycle closes the crack as in test II-5).

A great deal of difficulty was encountered when conducting the large stress range tests (i.e. tests $\mid 1-4$ and $\mid 1-5)$. The specimens had to be side grooved to control the plane and direction of cracking. Also optical crack length measurements showed very large surface growth rates that were not confirmed by the compliance measurements. Accordingly, a beach-mark procedure was used for tests $\|-4$ and II-5. Figure 8 shows the beach-marks for test II-4 and Figure 9 shows the beach-marks for test II-5. The beach-marks show that the cracks indeed are not straight and that the cracks grow faster on the surface than in the depth. It is clear though that the high stress tests are associated with a great deal of plasticity. An improved test technique is needed to get accurate data and a more complex correlation may be needed to relate the data to a simple function such as used in Equation (9). 
Two known uncertainties were intentionally introduced into these two tests. The first is the overload retardation and underload acceleration phenomena usually observed in low-alloy steel FCG rate testing. The second is the breakdown of the linear elastic fracture mechanics models that are envoked to lend credence to the $d a / d N$ versus $\Delta K$ correlations. It is precisely these concerns that leads to the need to restrict negative R-ratio benefits for applications satistying the ASME Boiler and Pressure Vessel Code because the Code allows stress ranges up to $2 S_{y}$. One of the important conclusions of this work is that extension of the positive R-ratio correlation developed by Eason et.al [1] conservatively bounds the high stress results obtained here.

\section{OTHER CONSIDERATIONS}

\section{a. Material Strength}

As crack closure plays the dominate role in negative R-ratio effects, it is apparent that plasticity induced closure effects are important in assessing negative R-ratio in FCG. With the exception of corrosion induced blunting, crack-tip blunting and crack-tip plasticity behavior are governed by the $K_{1} / S_{y}$ ratio of the material. Therefore it is expected that negative R-ratio effects are a function of the yield strength and cyclic plasticity behavior of the material. Indeed for a given $\Delta K_{1}$ and R-ratio, the higher the yield strength the more likely linear elastic fracture mechanics applies to the behavior and hence the greater benefit due to negative R-ratio effects. The test data reported herein may overestimate the negative R-ratio effect in situations involving higher $\mathrm{Kmax} / \mathrm{S}_{\mathrm{y}}$ ratios than tested here.

\section{b. Residual Stress Considerations}

The intention of this study is to qualify the expected beneficial effects of negative R-ratio for use in the FCG assessment of pressure vessel equipment. Such equipment is typically fabricated by welded construction. Even if stress relieved, such fabrication can induce residual stress states that alter the applied stress distribution. Thus, consideration of residual stress is essential for application of the benefits of negative R-ratio demonstrated by this test program.

\section{Stress Analysis Considerations}

Typically when design analysis parameters are in doubt regarding a certain aspect of a design, design parameters are chosen in such a way as to maximize the calculated stresses. However, when negative R-ratio effects are being taken into account in design calculations, assurance must be provided that the largest possible negative R-ratio (i.e., $R=-0.2$ is larger than $R=-0.5$ ) that is physically realizable is calculated. The final flaw size should be calculated on the design parameters which maximize the final flaw size. These conditions may not coincide with the set of conditions which produces the largest values of $\Delta K$. 
WAPD-T-2973

Page 9

\section{CONCLUSIONS}

The experimental results presented in this paper support the correlation of negative R-ratio results to the equation

$$
d a / d N=C F_{R} \Delta K^{n}
$$

where $F_{A}=[1.230 /(1.230-R)]^{n}$. For applications where the primary-plus-secondary stress difference ranges approach twice the yield strength, it is recommended that $F_{R}$ be set equal to the $F_{R}$ obtained for positive R-ratio tests, i.e. $F_{R}=[2.88 /(2.88-R)]^{n}$.

The above conclusions are applicable to low-alloy steels in air environments. Caution is expressed in the application of the beneficial effect of negative R-ratio effects to situations involving unknown residual stresses and to the possibility of over estimating the compressive stress due to normal engineering stress analysis practices.

\section{ACKNOWLEDGEMENTS}

The authors acknowledge the many useful discussions and help of Mr. L. A. James of Westinghouse Electric Corporation on the effects of negative R-ratio in fatigue crack growth. The help of Mr. R. E. Kolesar of Westinghouse in getting the B\&W tests completed and reported in a timely fashion is also acknowledged. 
WAPD-T-2973

Page 10

\section{REFERENCES:}

1. E. D. Eason, J. D. Gilman, D. P. Jones and S. P. Andrew, "Technical Basis for a Revised Fatigue Crack Growth Rate Reference Curve for Ferritic Steels in Air," Proceedings of 1988 ASME Winter Annual Meeting Fatigue Initiation. Propagation, and Analysis for Code Construction, editor M. Pager, MPC-Vol. 29, ASME Document No. G00499, November 1988.

2. H. Lange, T. Fett and D. Munz, "Fatigue Crack Propagation Under Loading With Negative R-ratio," Mat.-wiss. U. Werkstofftech, Vol. 21, 1990 pps. 169-173.

3. M. Kurihara, A. Katoh and M. Kawahara, "Analysis on Fatigue Crack Growth Rates Under a Wide Range of Stress Ratios," ASME J. Of Pressure Vessel Technology, Vol. 108 May 1986, pp 209-213.

4. R. O. Ritchie and S. Surash, "Some Considerations on Fatigue Crack Closure Induced Fracture Surface Morphology," Metallurigical Transactions, Vol. 13A, 1982.

5. "Standard Test Method for Measurement of Fatigue Crack Growth Rates," 1991 Annual Book of ASTM Standards, Americal Society for Testing and Standards E647-91, Philadelphia, PA, 1991.

6. "Standard Test Method for Plane-Strain Fracture Toughness of Metallic Materials," 1990 Annual Book of ASTM Standards, American Society for Testing and Standards, E39983, Vol. 03.01, Philadelphia, PA, 1990.

7. H. Tada, P. C. Paris and G. R. Irwin, The Stress Analysis of Cracks Handbook, Del Research Corporation, Hellertown, PA, 1973.

8. D. W. Marquardt, "An Algorithm for Least - Squares Estimation of Non-Linear Parameters," J. of Soc. Indust. and Applied Math., Vol. 11, No. 2, (1963) pp. 431-441. 


\section{Table I}

Chemical Composition and Mechanical Froperties of Material Tested

\begin{tabular}{|c|c|c|c|c|c|c|c|c|c|c|}
\hline $\begin{array}{l}C \\
0.18\end{array}$ & $\begin{array}{l}\mathrm{Mn} \\
0.65\end{array}$ & $\begin{array}{l}P \\
0.005\end{array}$ & $\begin{array}{l}S \\
0.008\end{array}$ & $\begin{array}{l}S i \\
0.24\end{array}$ & $\begin{array}{l}\mathrm{Ni} \\
0.83\end{array}$ & $\begin{array}{l}\mathrm{Cr} \\
0.34\end{array}$ & $\begin{array}{l}\text { Mo } \\
0.69\end{array}$ & $\begin{array}{l}v \\
0.03\end{array}$ & $\begin{array}{l}\text { A1 } \\
0.003\end{array}$ & $\begin{array}{l}\mathrm{Cu} \\
0.07\end{array}$ \\
\hline $\begin{array}{l}\text { Co } \\
0.008\end{array}$ & $\begin{array}{l}\mathrm{Ti} \\
0.001\end{array}$ & $\begin{array}{l}A_{1} \\
0.010\end{array}$ & $\begin{array}{l}s_{b} \\
0.003\end{array}$ & $\begin{array}{l}\mathrm{Bi} \\
0.001\end{array}$ & $\begin{array}{l}\text { Cd } \\
<0.005\end{array}$ & $\begin{array}{l}P_{b} \\
<0.0005\end{array}$ & & & & \\
\hline
\end{tabular}

Results B\&W Mechanical Tests

\begin{tabular}{|c|c|c|}
\hline $\begin{array}{c}\text { Yield Stress } \\
\text { (psi) }\end{array}$ & $\begin{array}{c}\text { Ultimate Stress } \\
\text { (psi) }\end{array}$ & $\begin{array}{c}\text { \& } \\
\text { Elongation }\end{array}$ \\
\hline 76,300 & 88,900 & 25.0 \\
66,200 & 86,000 & 25.0 \\
75,200 & 92,600 & 24.0 \\
\hline
\end{tabular}

Average Yield Stress $=72,600$ psi

Material: $\mathrm{A} 508 \mathrm{Cl} .2$

Supplier: National Forge Company

Heat Number: 216619 


\section{Table II}

\section{Test Matrix}

Phase I

Initial Values

\begin{tabular}{|c|c|c|c|c|c|}
\hline Test & $a$ & $\sigma_{\max }$ & $\Delta \sigma /$ Sy & $\Delta K^{\star}$ & R-Ratio \\
\hline $1-1$ & 0.4490 & 15,500 & 0.21 & 20,000 & 0 \\
\hline $1-2$ & 0.4520 & 15,500 & 0.43 & 40,000 & -1.0 \\
\hline $1-3$ & 0.4520 & 15,500 & 0.32 & 30,000 & -0.5 \\
\hline $1-4$ & 0.4490 & 15,500 & 0.64 & 60,000 & -2.0 \\
\hline $1-5$ & 0.3120 & 42,900 & 1.18 & 65,000 & -0.5 \\
\hline $1-6$ & 0.3070 & 42,900 & 1.18 & 87,600 & -1.0 \\
\hline
\end{tabular}

Phase II

Initial Values

\begin{tabular}{|c|c|c|c|c|c|l||}
\hline Test & $a$ & $\sigma_{\max }$ & $\Delta \sigma /$ Sy & $\Delta K^{\star}$ & R-Ratio & Control \\
\hline II-1 & 0.155 & 20,700 & 0.57 & 30,000 & -0.5 & Load \\
\hline II-2 & 0.146 & 20,700 & 0.57 & 30,000 & -1.0 & Load \\
\hline II-3 & 0.153 & 13,800 & 0.38 & 30,000 & -1.0 & Deflection \\
\hline$\| 1-4$ & 0.183 & 84,500 & 2.33 & 120,000 & -1.0 & Deflection ${ }^{\star \star}$ \\
\hline$\| 1-5$ & 0.178 & 95,500 & 2.63 & 120,000 & -1.0 & Deflection $^{\star \star \star}$ \\
\hline
\end{tabular}

*Target values

**First cycle opens crack

$\star \star \star$ First cycle closes crack 
Table III

Regression Analysis Results

a. Phase 1

\begin{tabular}{||l|l|l|c|c|c|c||}
\hline Test & R-Ratio & $C_{1}$ & $n$ & $\bar{C}_{1}$ & $\bar{n}^{(1)}$ & \multicolumn{1}{|c|}{${\overline{F_{\mathrm{R}}}}_{1} / \bar{C}_{\mathrm{o}}$} \\
\hline I-1 & 0 & $1.5980 \times 10^{-19}$ & 3.0540 & $1.2298 \times 10^{-19}$ & 3.0789 & 1.0000 \\
\hline $1-2$ & -1.0 & $2.1486 \times 10^{-21}$ & 3.2631 & $1.6847 \times 10^{-20}$ & 3.0789 & 0.1370 \\
\hline $1-3$ & -0.5 & $5.6072 \times 10^{-20}$ & 3.0483 & $4.0169 \times 10^{-20}$ & 3.0789 & 0.3266 \\
\hline $1-4$ & -2.0 & $1.5111 \times 10^{-20}$ & 2.9744 & $4.5564 \times 10^{-21}$ & 3.0789 & 0.0371 \\
\hline $1-5$ & -0.5 & $3.5663 \times 10^{-22}$ & 3.4807 & $3.5990 \times 10^{-20}$ & 3.0789 & 0.2926 \\
\hline $1-6$ & -1.0 & $7.8702 \times 10^{-22}$ & 3.3328 & $1.5582 \times 10^{-20}$ & 3.0789 & 0.1267 \\
\hline
\end{tabular}

b. Phase II

\begin{tabular}{||l|l|l|l|l|l|l||}
\hline Test & R-Ratio & $\mathrm{C}_{1}$ & $\mathrm{n}$ & $\bar{C}_{1}$ & $\bar{n}^{(1)}$ & \multicolumn{1}{c||}{${\overline{F_{\mathrm{R}}}}_{1} / \bar{C}_{0}$} \\
\hline$\| 1-1$ & -0.5 & $1.6436 \times 10^{-18}$ & 2.7276 & $3.4557 \times 10^{-20}$ & 3.0789 & 0.2810 \\
\hline$\| 1-2$ & -1.0 & $6.2673 \times 10^{-19}$ & 2.7502 & $1.6545 \times 10^{-20}$ & 3.0789 & 0.1345 \\
\hline$\| 1-3$ & -1.0 & $3.5450 \times 10^{-13}$ & 1.475 & $9.8220 \times 10^{-21}$ & 3.0789 & 0.0799 \\
\hline$\| 1-4$ & -1.0 & $1.3776 \times 10^{-21}$ & 3.3656 & $3.6393 \times 10^{-20}$ & 3.0789 & 0.2959 \\
\hline$\| 1-5$ & -1.0 & $1.5037 \times 10^{-14}$ & 1.9650 & $4.9562 \times 10^{-20}$ & 3.0789 & 0.4030 \\
\hline
\end{tabular}

NOTES:

(1) $\bar{n}=$ Average value of $n$ from Tests $1-1$ through $11-2$

$$
\begin{aligned}
& \bar{n}=\frac{3.0540+3.2631+3.0483+2.9744+3.4807+3.3328+2.7276+2.7502}{8} \\
& \bar{n}=3.0789
\end{aligned}
$$

(2) $\bar{C}_{0}=1.2298 \times 10^{-19}$ 
Table IV

Statistical Analysis Results

of Negative R-Ratio Effects

\begin{tabular}{||l|l|l|l|l||}
\hline $\begin{array}{l}\text { Data } \\
\text { Point }\end{array}$ & $\begin{array}{l}\text { Source } \\
\text { Test \# }\end{array}$ & R-Ratio & $F_{\mathrm{R}}$ & $\begin{array}{l}F_{\mathrm{R}} \\
\text { Predicted }^{*}\end{array}$ \\
\hline 1 & I-1 & 0.0 & 1.00 & 1.000 \\
\hline 2 & $1-2$ & -1.0 & 0.1370 & 0.1601 \\
\hline 3 & $1-3$ & -0.5 & 0.3266 & 0.3498 \\
\hline 4 & $1-4$ & -2.0 & 0.0371 & 0.0512 \\
\hline 5 & $1-5$ & -0.5 & 0.2926 & 0.3498 \\
\hline 6 & $1-6$ & -1.0 & 0.1267 & 0.1601 \\
\hline 7 & $11-1$ & -0.5 & 0.2810 & 0.3498 \\
\hline 8 & $11-2$ & -1.0 & 0.1345 & 0.1601 \\
\hline 9 & $11-3$ & -1.0 & 0.0799 & 0.1601 \\
\hline 10 & $11-4$ & -1.0 & 0.2559 & 0.1601 \\
\hline 11 & $11-5$ & -1.0 & 0.4030 & 0.1601 \\
\hline
\end{tabular}

$F=[A /(A-R)]^{3.0789}$

$A=1.22986 ;$ Standard Deviation $=0.09743688$

${ }^{\star}$ Predicted from equation $F_{R}=[1.22986 /(1.22986-R)]^{3.0789}$ 
Figito

sed "xulte and "asi specimen sonicuretion

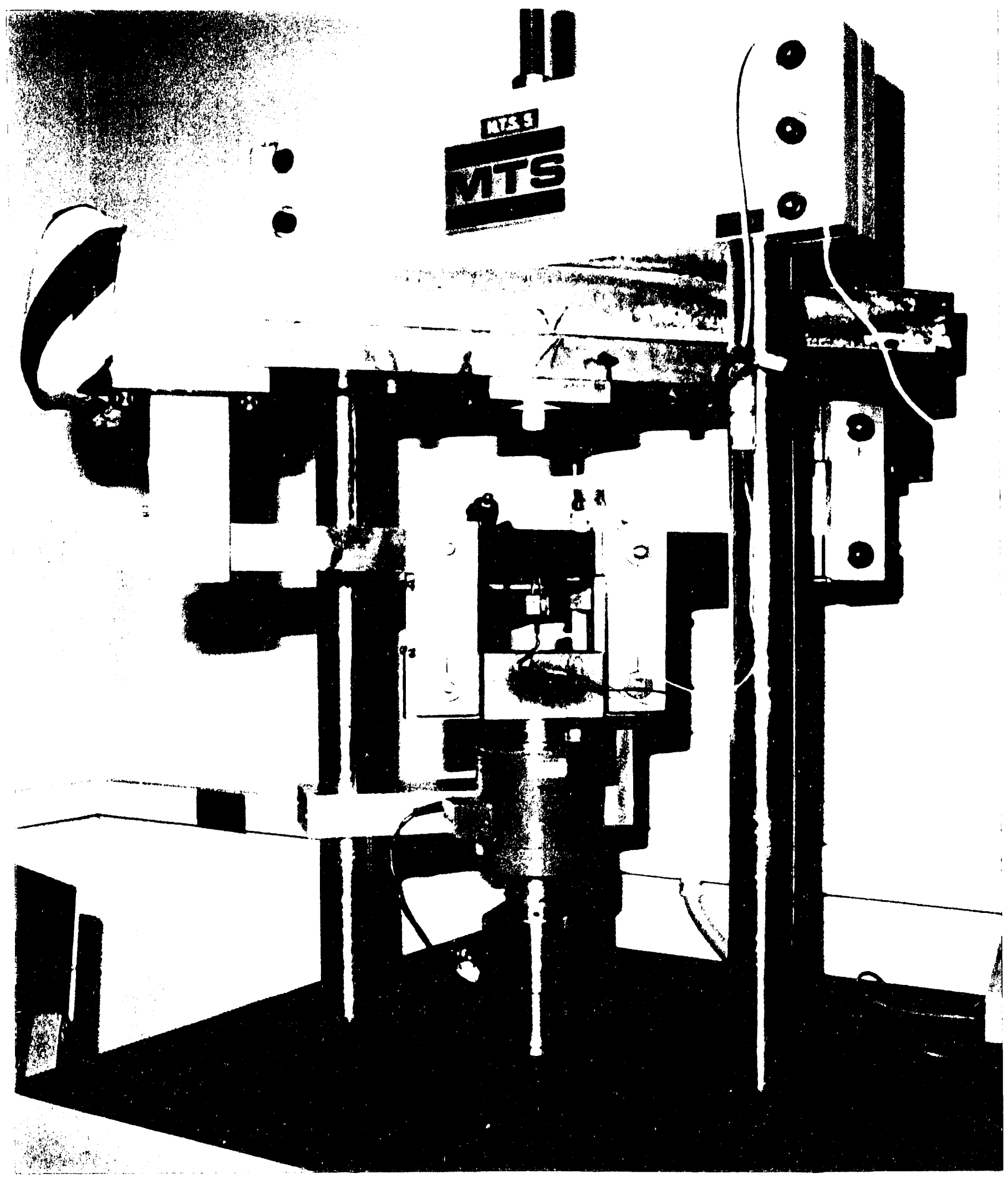


WAPD-T-2973

Page 16

Figure 2

a. Test Specimen Design for Phase I

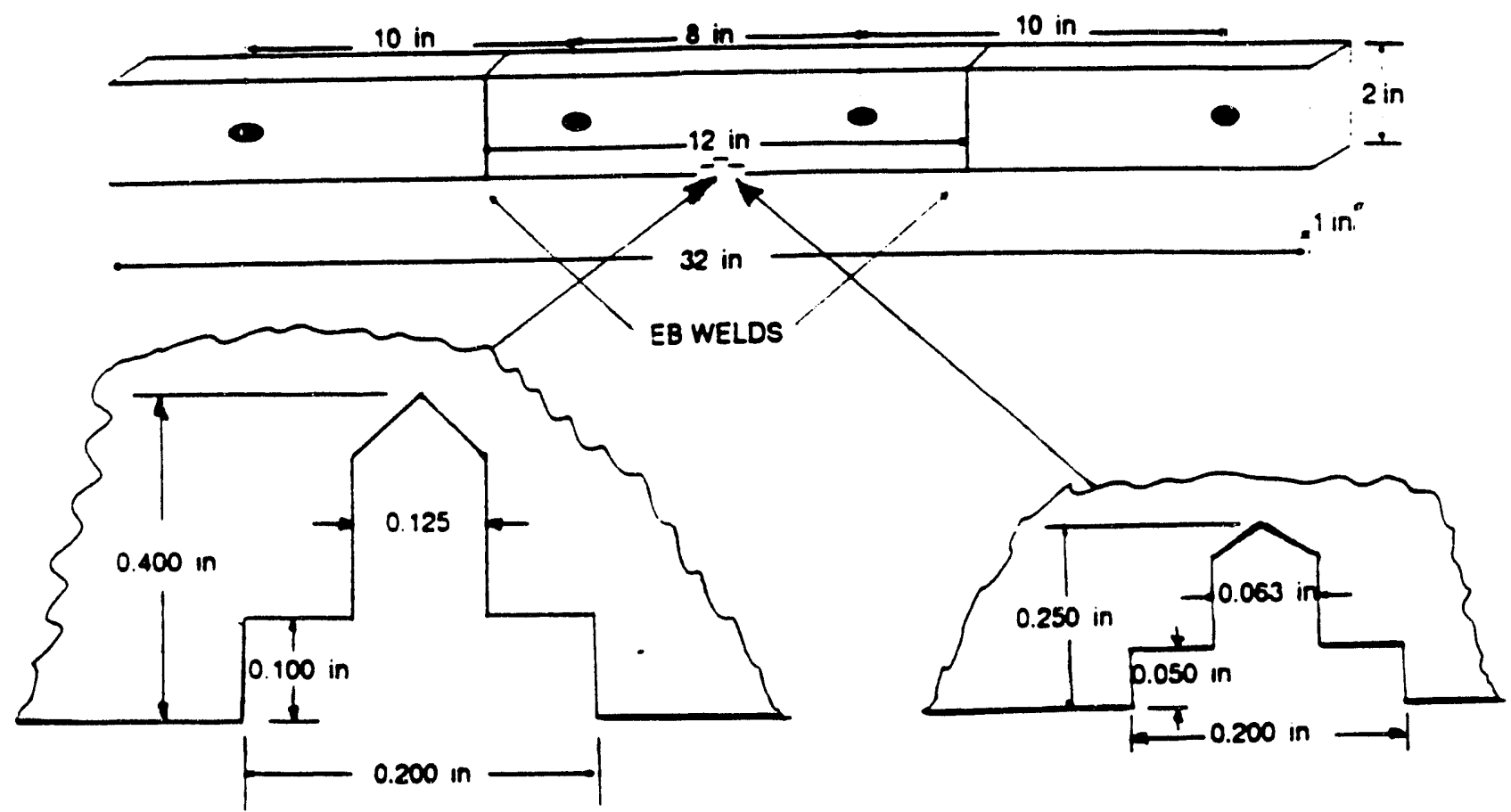

b. Test Specimen Design for Phase II
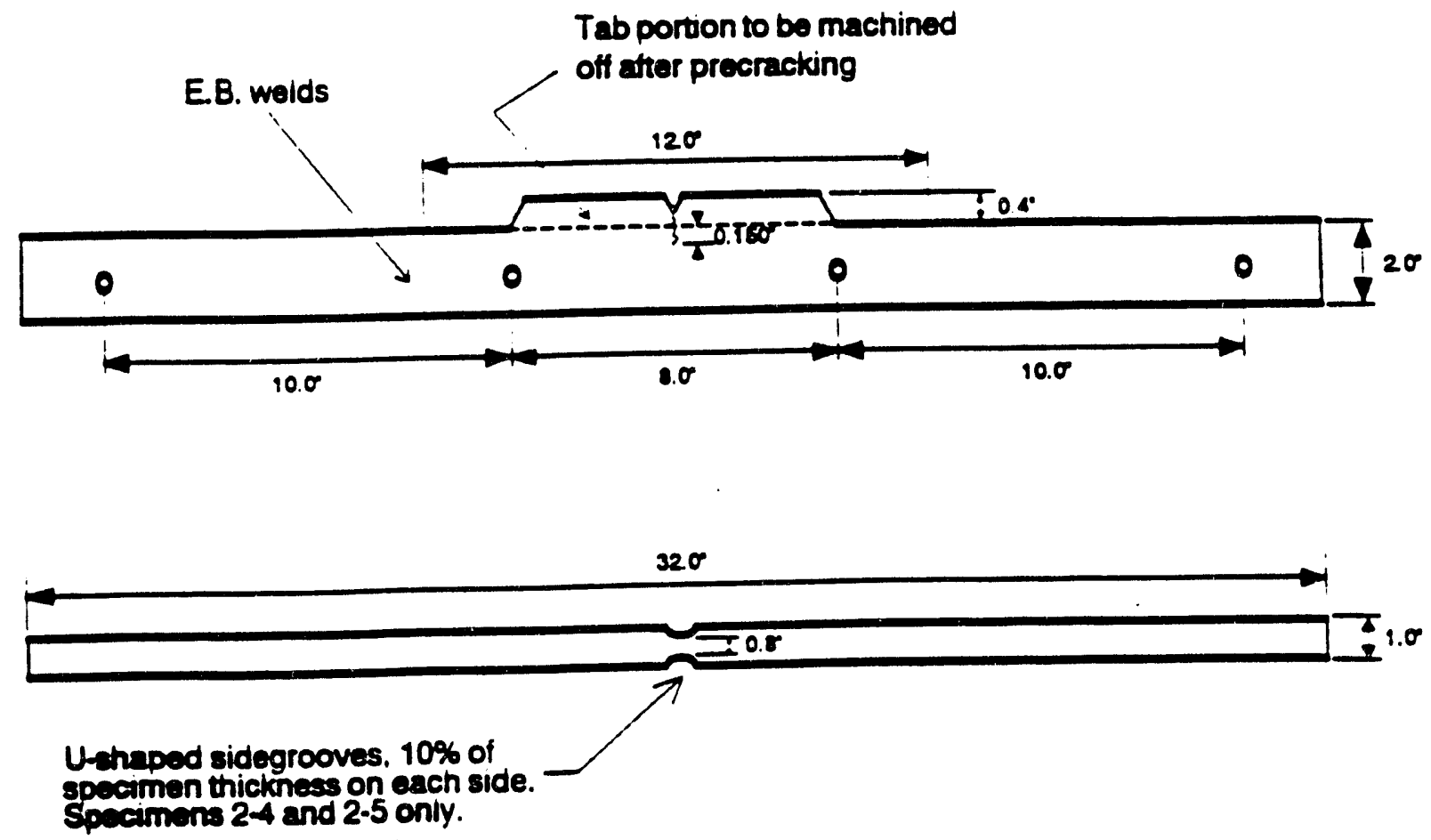
WAPD-T-2973

Page 17

Figure 3. Fatigue Crack Growth Rate Versus Delta-K for Tests 1-1 Through 1-6, $\|-1$, and $\|-2$.

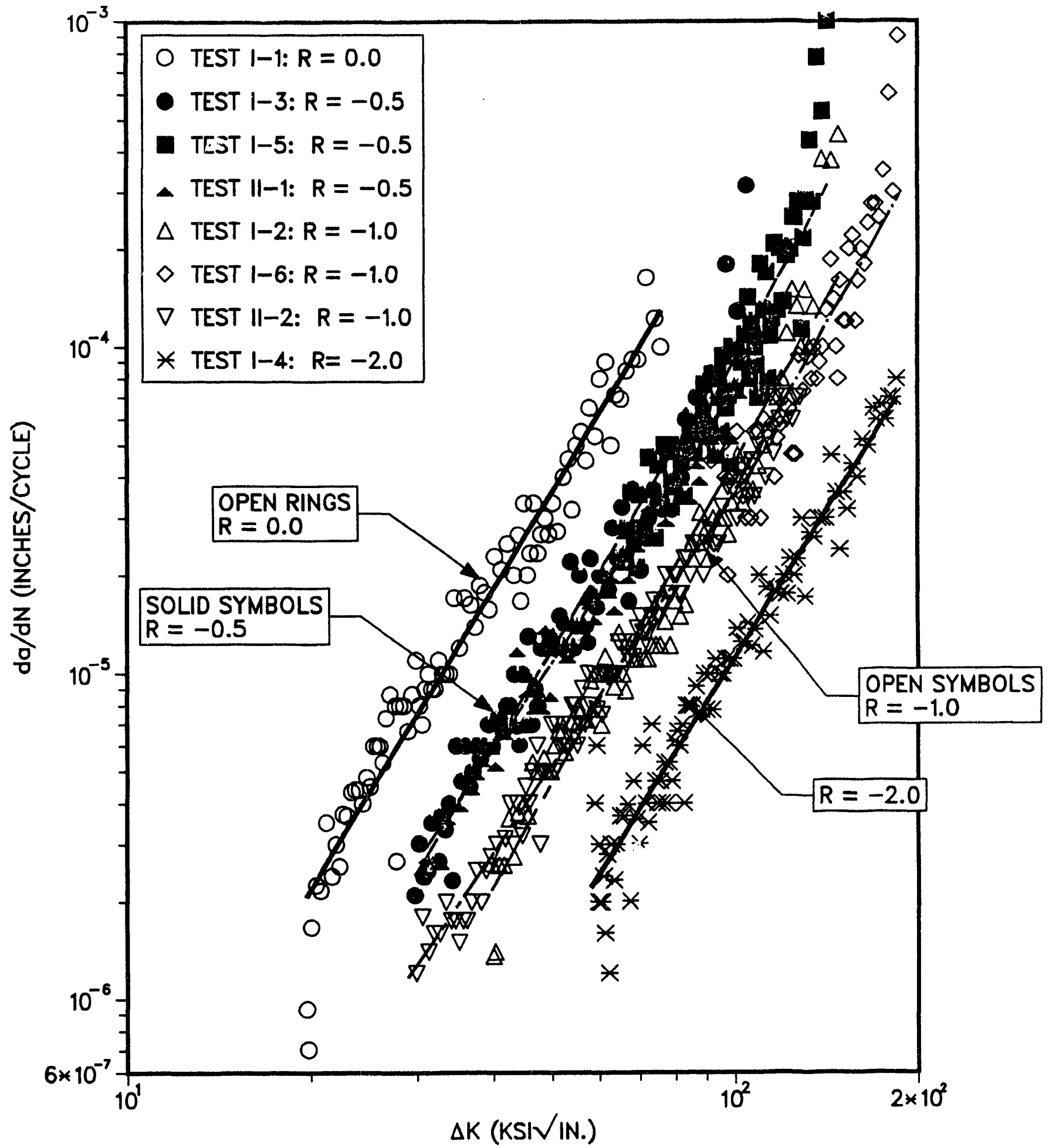

TAG FILE: R2739.F04;1 
WAPD-T-2973

Page 18

Figure 4. Normalized Fatigue Crack Growth Rate Versus R-Ratio for A508 Cl. 2.

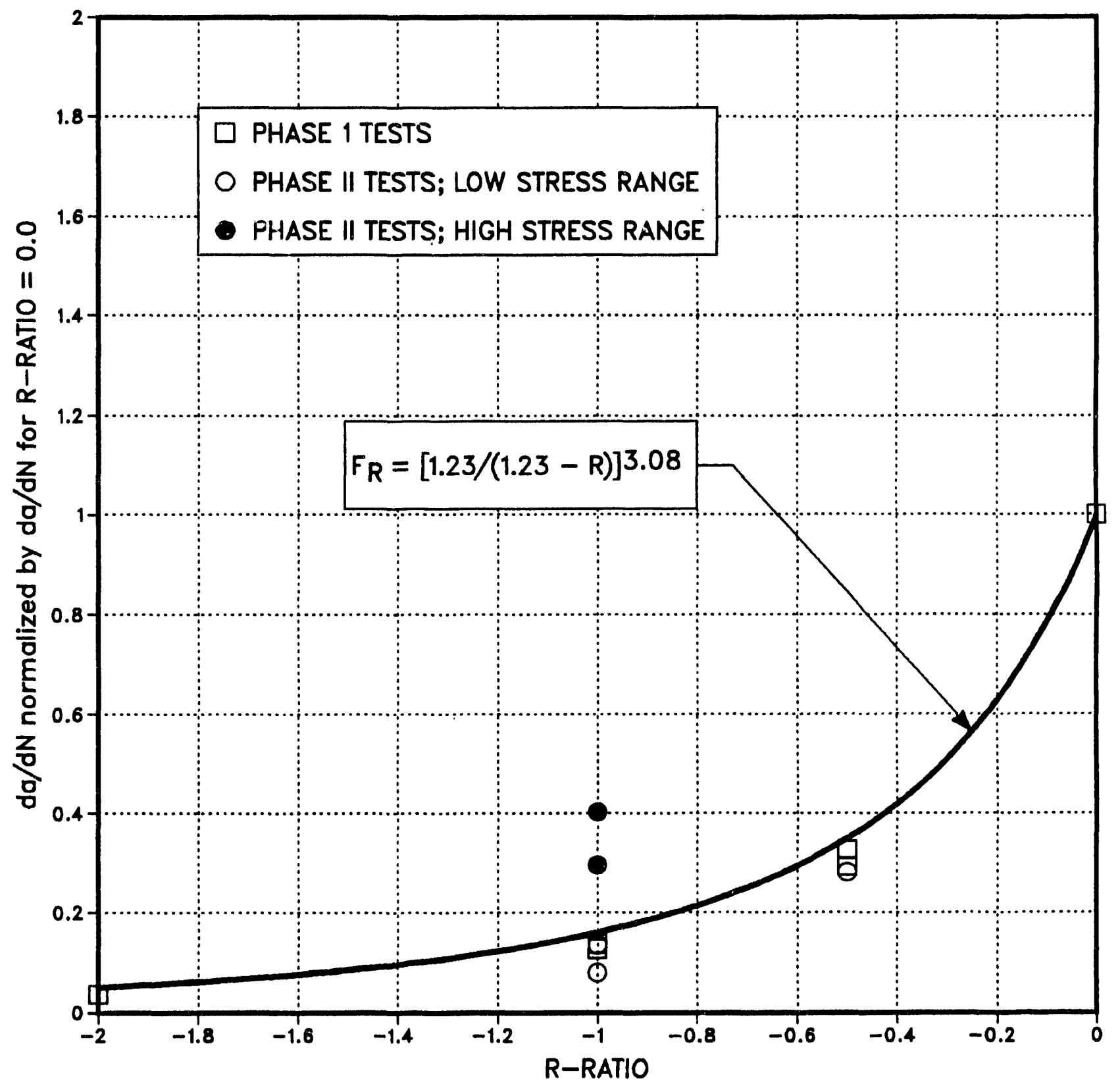


Figure 5

Negative R-Ratio Data Compared to Eason Model.

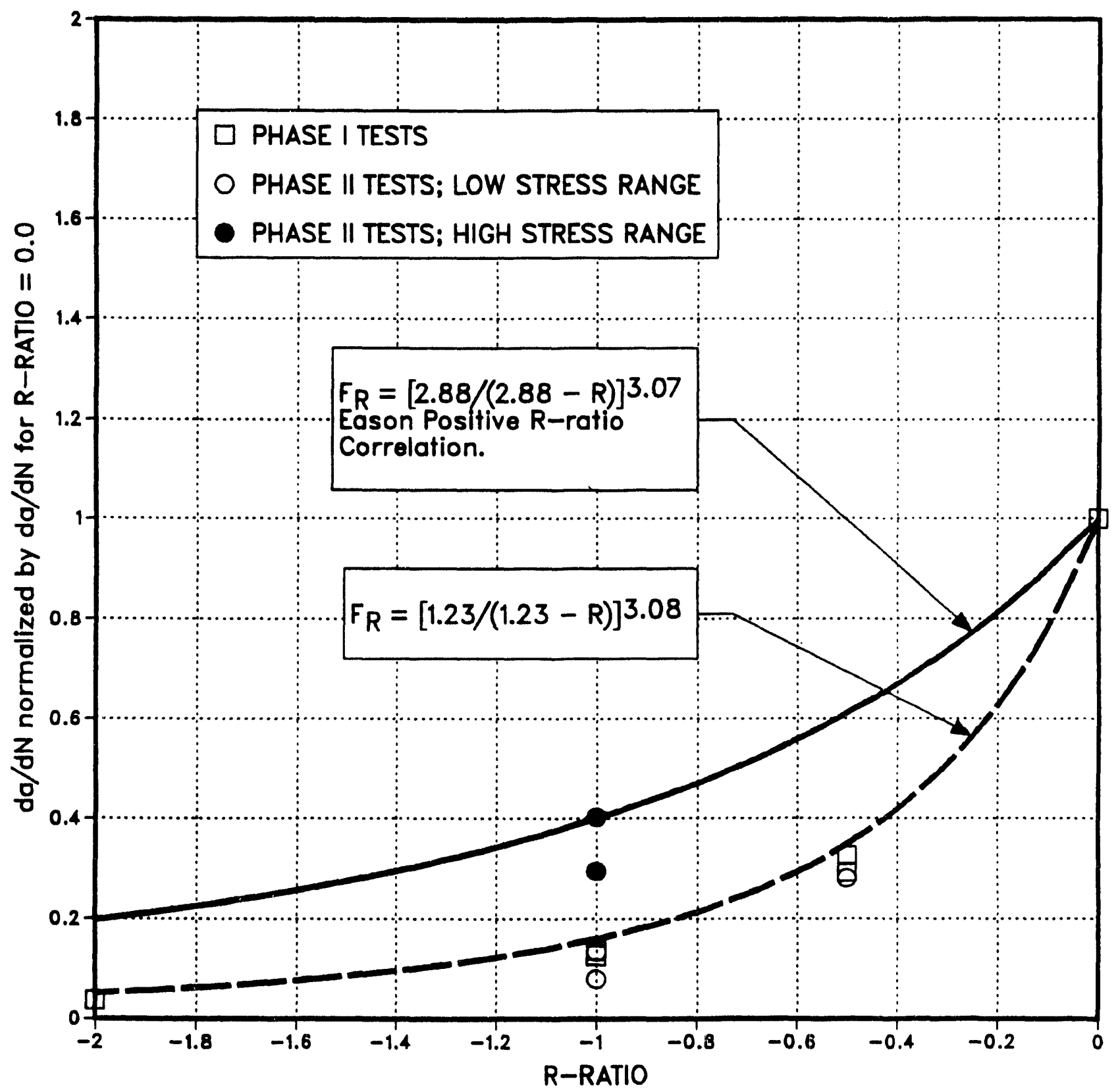

TAG FILE: R2739.F08;1 
WAPD-T-2973

Page 20

Figure 6. Effect of Notch Versus Tight Crack Geometries on the Fatigue Crack Growth Rates for Negative R-ratios.

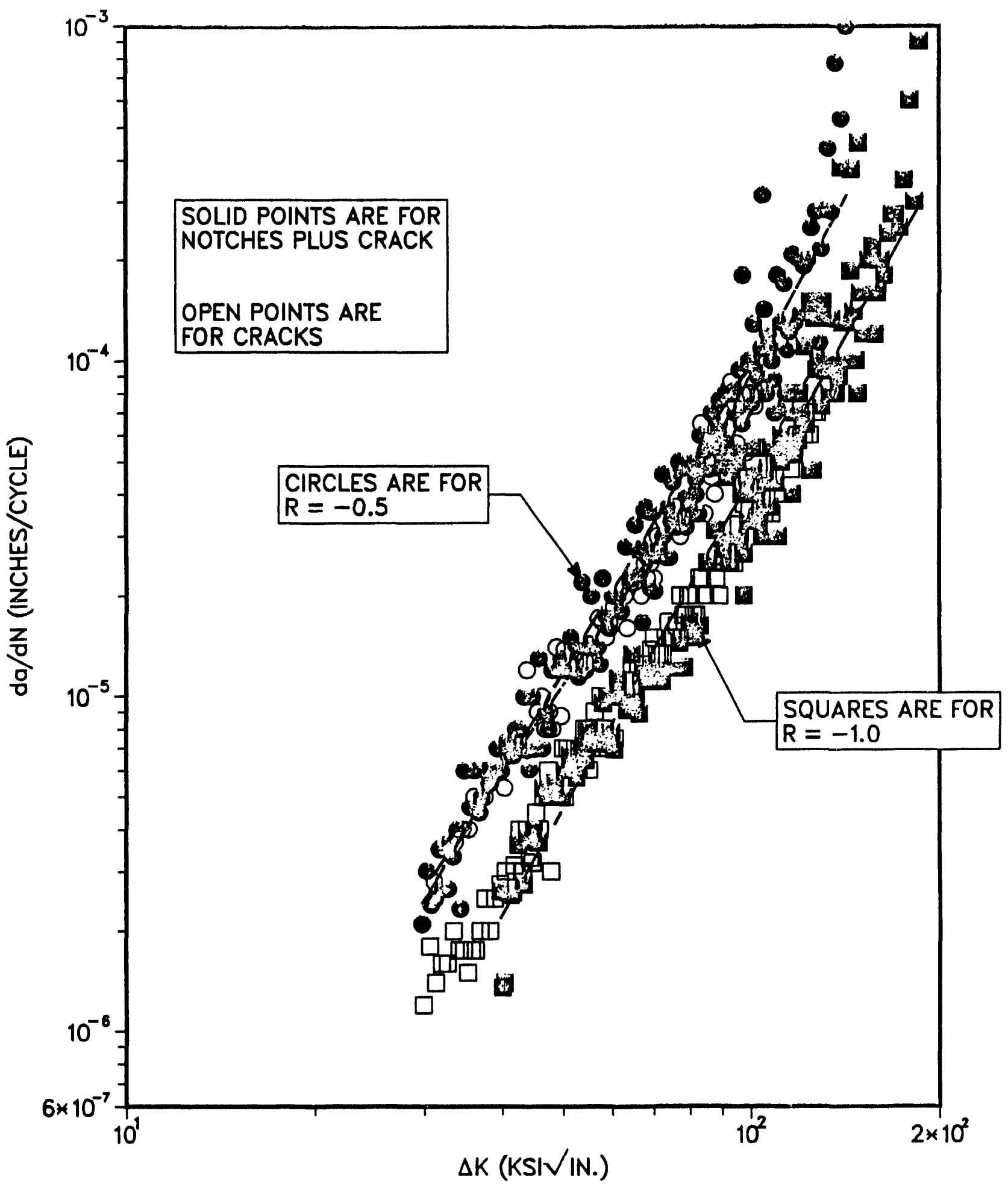


WAPD-T-2973

Page 21

Figure 7. Fatigue Crack Growth Rate Versus Delta-K for $\mathrm{R}=-1.0$

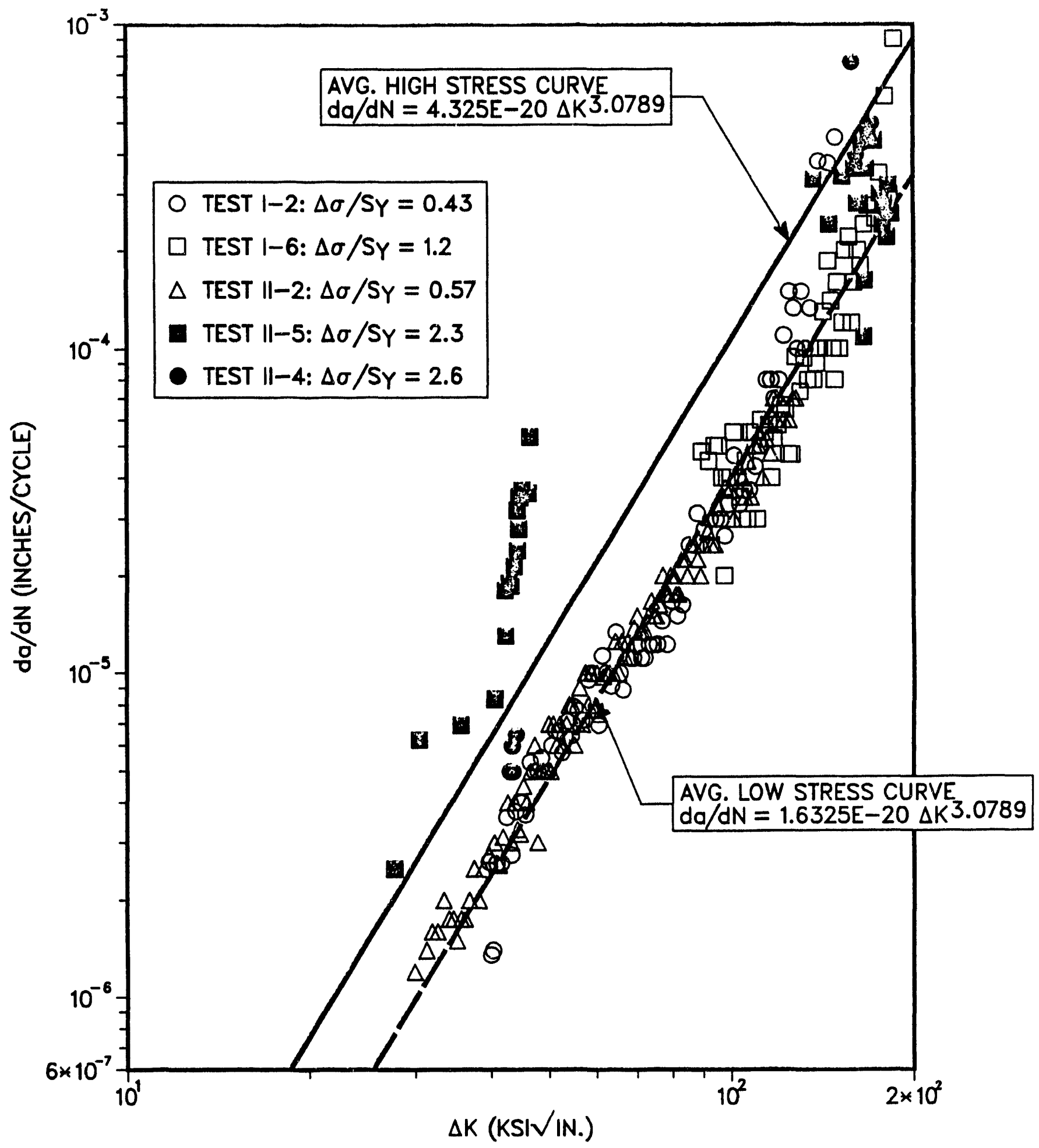




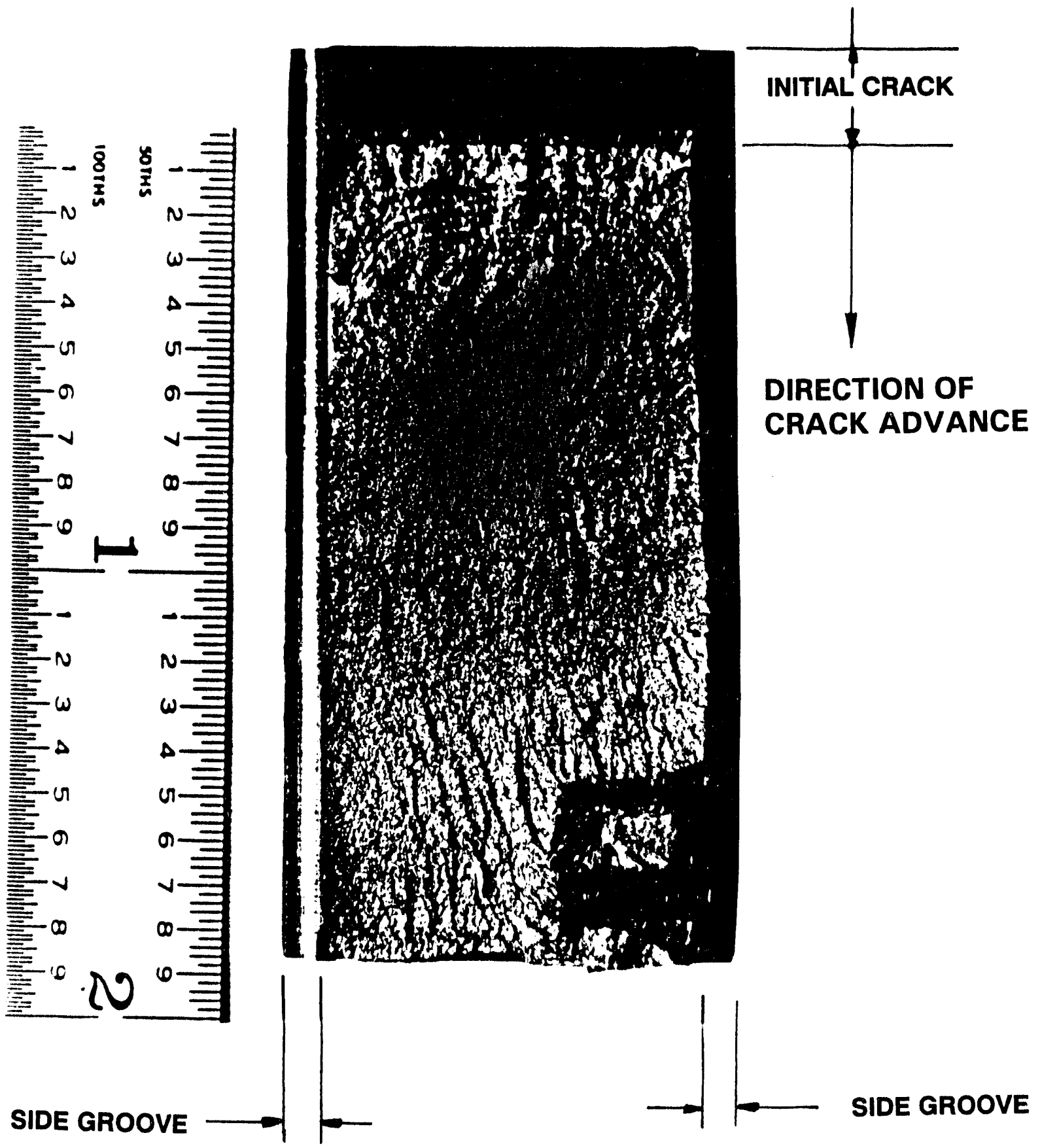




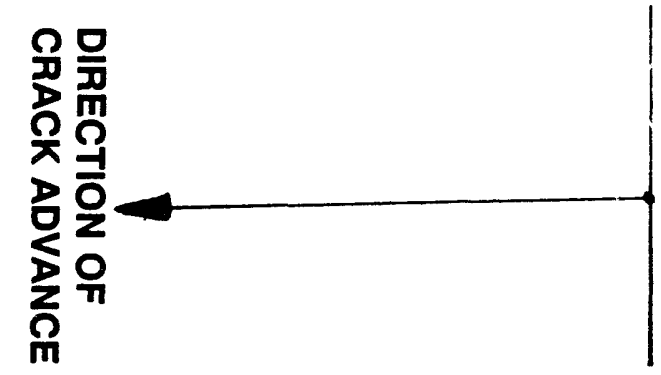

Pan

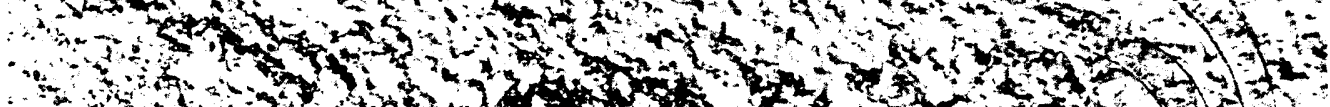

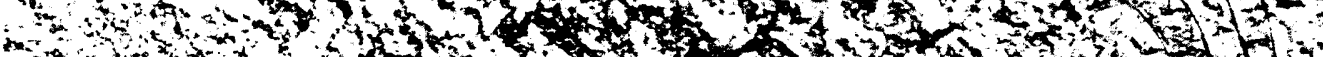

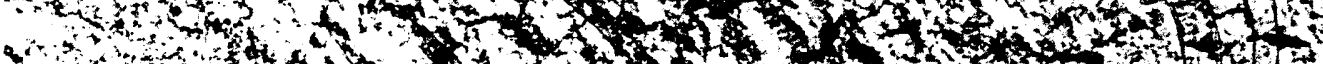

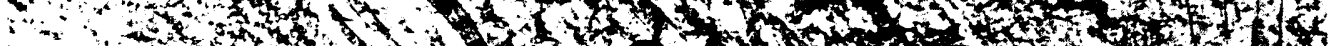

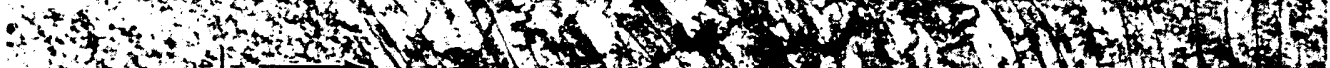

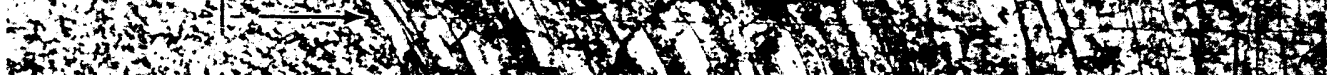

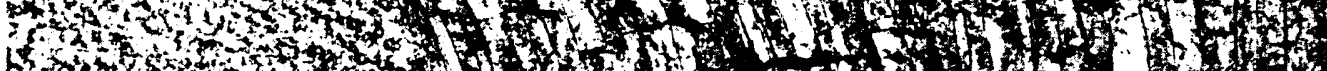

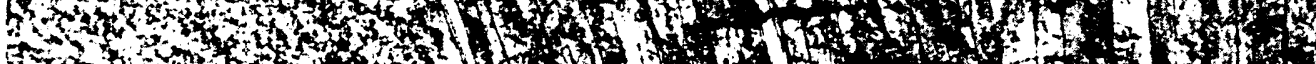

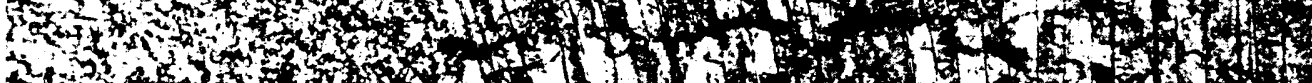

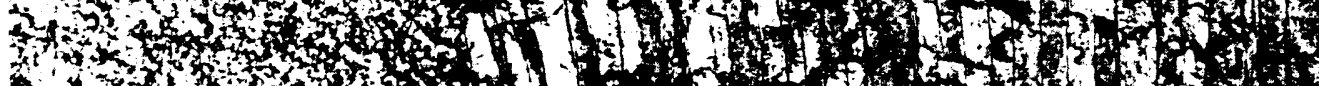

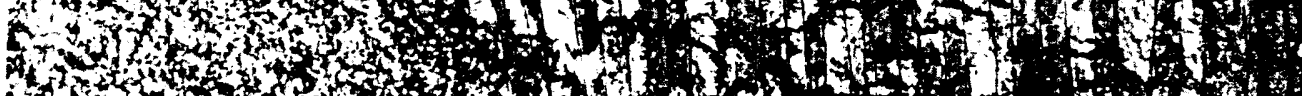

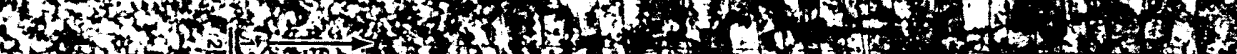

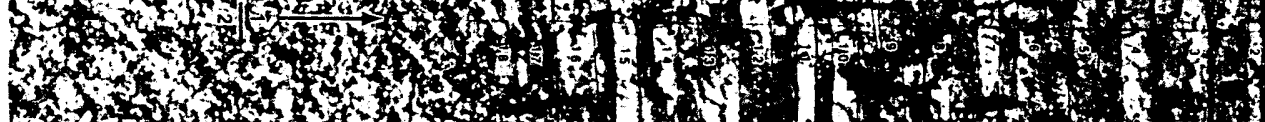

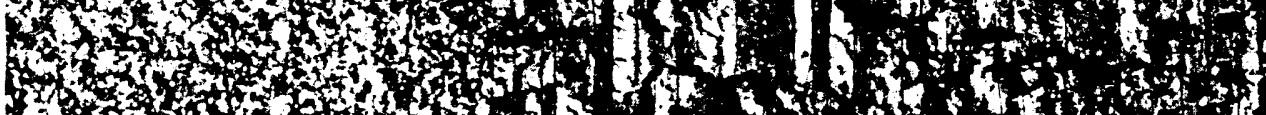

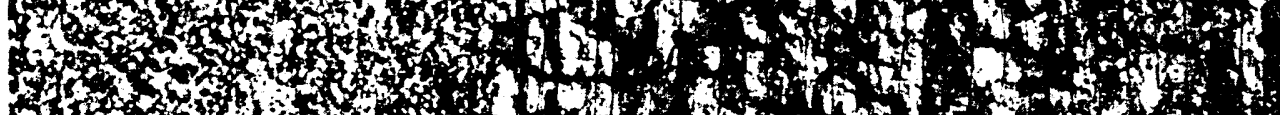

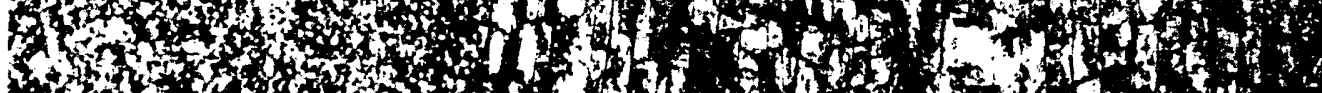

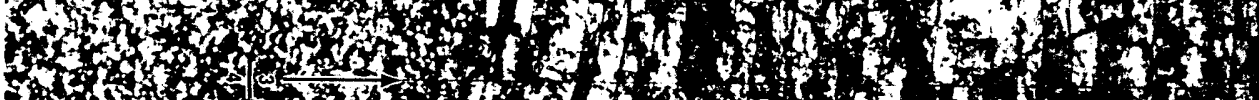

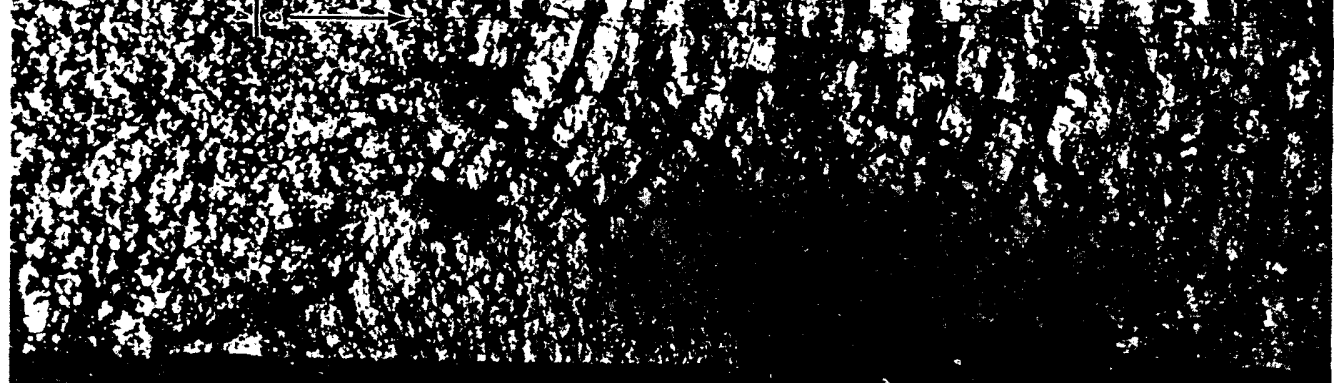

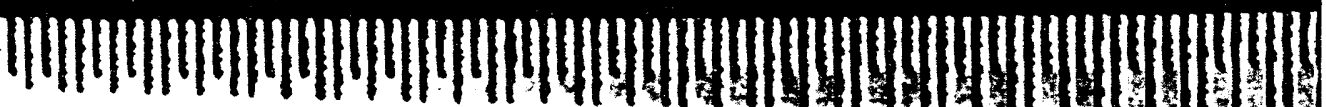


